УДК 378.4:32(410.1)

DOI:

Ірина Брандибура, аспірант кафедри іноземних мов Національного університету “Львівська політехніка"

\title{
ПРОФЕСІЙНА ПІДГОТОВКА БАКАЛАВРІВ ПОЛІТОЛОГІЇ В УНІВЕРСИТЕТАХ АНГЛІЇ ТА УЕЛЬСУ: ТЕОРІї, КОНЦЕПЦІї, ПІДХОДИ
}

У статті проаналізовано поняттєво-категорійний апарат з досліджуваної проблеми (професійна підготовка, політологія, фахівець-політолог), а також основні соиіо-ідеологічні засади, теорії, концепції, підходи, щя лежать в основі професійної підготовки бакалаврів гуманітарних наук з політології 6 університетах Англії та Уельсу, зокрема економічна ефективність, прогресивізм, когнітивний плюралізм, соціальний реконструктивізм, теорії когнітивізму, конструктивізму, концепція активного навчання, компетентнісний, міжкультурний, міждисциплінарний, аксіологічний підходи.

Ключові слова: професійна підготовка; політологія; фахівець-політолог; економічна ефективність; прогресивізм; когнітивний плюралізм; сочіальний реконструктивізм; теорії когнітивізму; конструктивізму; концепція активного навчання; компетентнісний; міжкультурний; міждисциплінарний; аксіологічний підходи.

Jim. 17.

Iryna Brandybura, Applicant of the Foreign Languages Department, Lviv Polytechnic National University

\section{PROFESSIONAL TRAINING OF BACHELORS IN POLITICALSCIENCE AT THE UNIVERSITIES OF ENGLAND AND WALES: THEORIES, CONCEPTS, APPROACHES}

The article analyzes key notions of the problem under research (professional training, political science, political scientist), as well as main ideologies, theories, concepts, approaches underling professional training of Bachelors of Art in Political Science at the universities of England and Wales, namely economic efficiency, progressivism, social reconstructivism, cognitive pluralism, theories of cognitivism and constructivism, active learning, competency-based, intercultural, interdisciplinary, axiological approaches.

Based on the analysis of research literature, we conclude that political science as a subject area and a professional domain is a multifaceted notion that can be broadly defined as a systemic study of authority using theoretical and empirical methods. Theoretical political science originates from history and philosophy, and focuses on the critical analysis of political institutions' development, while applied political science is closely related to economics, management, law, and focuses on government and public administration. Methodological tools of modern political science include qualitative methods used in social anthropology, quantitative methods used in econometrics and psychometrics, as well as mathematical modeling used in economics. Such methodological diversity is considered as its strength as political science graduates acquire competences valuable in various professional areas that create a wide range of employment opportunities.

As a result of the conducted research, we conclude that professional training of Bachelors of Art in Political Science at the universities of England and Wales is based on complex integration of philosophical, psychological, educational theories, concepts, and approaches (social and economic efficiency, progressivism, cognitive pluralism, social reconstructivism, theories of cognitivism and constructivism, active learning, competency-based, intercultural, interdisciplinary, axiological approaches), which ensure quality training for professional and research activities, development of high-level intellectual, communicative, interpersonal skills, social and democratic values, sense of global citizenship, as well as foster graduate's personal integrity.

Keywords: professional training; political science; political scientist; economic efficiency; progressivism; cognitive pluralism; social reconstructivism; theories of cognitivism; constructivism; active learning; competencybased; intercultural; interdisciplinary; axiological approaches.

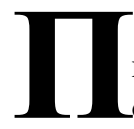
остановка проблеми. Професійна підготовка політологів вважається одним із важливих напрямів розвитку сучасної вищої освіти на теренах України, що зумовлено необхідністю всебічного дослідження владно-політичних процесів на місцевому, національному та глобальному рівнях, які кардинально змінились у зв'язку із демократизацією суспільного життя, зростанням політичної культури громадян, активними процесами інтеграції тощо.

Одним із цінних джерел для визначення стратегічних напрямів розвитку університетської системи в Україні є аналіз розвитку освіти за кордоном. У цьому контексті науковий інтерес становить досвід Англії та Уельсу, в яких система 
вищої освіти має глибокі історичні корені, здобула світове визнання за високі якісні показники, сприяє стабільності держави, гармонійно поєднує національні традиції й світові освітні тенденції.

Аналіз актуальних досліджень i публікацій свідчить про те, науковці вивчають різноманітні аспекти професійної підготовки політологів, а саме: зміст професійної підготовки політологів (Г. Севігні (H. Savigny), К. ГормліГенан (C. Gormley-Heenan); моделі, методи i форми професійної підготовки політологів (К. ЛестонБандеіра (C. Leston-Bandeira), C. Куртіс (S. Curtis), Дж. Бріпс (J. Briggs); впровадження інформаційнокомунікаційних технологій у процес професійної підготовки політологів (C. Торнтон (S. Thornton), C. Poфе (S. Rofe), Д. Міддлтон (D. Middleton); підходи, принципи та методи оцінювання (А. Блер (A. Blair), C. MarГiнті (S. McGinty); специфіка підготовки студентів-політологів до науководослідної діяльності (С. Лайтфут (S. Lightfoot), Дж. Паркер (J. Parker). Однак чимало аспектів потребують подальшого вивчення і наукового обгрунтування.

Метою статті $\epsilon$ аналіз поняттєвокатегорійного апарату з досліджуваної проблеми та основних соціо-ідеологічних засад, теорій, концепцій, підходів, на яких базується професійна підготовка бакалаврів гуманітарних наук 3 політології в університетах Англії та Уельсу.

Виклад основного матеріалу. У сучасній науково-педагогічній літературі поняття “професійна підготовка" трактується науковцями як: “оволодіння сукупністю спеціальних знань, навичок і вмінь, які дають можливість виконувати роботу в галузі певної професійної діяльності" [ 1 , 171]; “сформовану єдність трьох компонентів: професійної спрямованості, професійної компетентності і професійної кваліфікації' $[2,53]$. Таким чином, професійна підготовка - це комплекс заходів, спрямованих на отримання кваліфікації відповідно до обраної спеціальності, що забезпечать готовність до професійної діяльності.

Оскільки специфіка організації професійної підготовки значною мірою залежить від галузі, на яку вона спрямована, вважаємо доцільним розглянути політологію як галузь знань і сферу професійної діяльності. Аналіз наукових підходів і тлумачень поняття “політологія” дозволяє стверджувати, що воно $є$ надзвичайно широким i багатогранним, однак, в узагальненому варіанті, означає "системне вивчення управління за допомогою емпіричних і теоретичних методів аналізу”. У традиційному розумінні, політологія досліджує державу, її органи та інститути влади, однак сучасна політологія має значно ширше предметне поле та охоплює вивчення усіх соціальних, культурних і психологічних факторів, які впливають на функціонування державних органів влади [10].

Теоретична політологія покладається на історичні та філософські витоки цієї дисципліни. Такий підхід ставить політологію у сферу гуманітарних наук і спрямовує студентів на вивчення розвитку політичних інститутів і їх критичну оцінкуна основі знань про політичні ідеї. Прикладна політологія спрямована на професійну діяльність у сфері публічного адміністрування. Вона тісно пов'язана 3 такими дисциплінами як економіка, менеджмент, право і зосереджується на вивченні урядових процесів [8, 43].

Багато науковців стверджують, що таке методологічне різноманіття слід розглядати як сильну сторону політології. Методологічний інструментарій сучасної політології включає якісні методи, які передбачають строгий набір критеріїв для осмислення політичних суб'єктів і процесів на зразок соціальної антропології, а також кількісні методи, спрямовані на обробку даних способами близькими до тих, що використовуються в економетриці та психометриці, і математичне моделювання, що знаходимо в економіці. Такою $€$ загальна природа політології як галузі знань [15].

Результатом професійної підготовки бакалаврів політології є фахівець-політолог. Вища освіта політологічного спрямування забезпечує формування професійних компетентностей, які $\epsilon$ цінними у багатьох галузях, що створює широкі можливості працевлаштування. Політологи можуть працювати у таких галузях: політика, журналістика, дослідницька діяльність тощо. Відповідно до Стандартної класифікації професій (англ. Standard Occupational Classification), фахівці у галузі політології можугь професійно реалізувати себе як: керівники та високопосадовці, виборні чиновники і представники, науковці у галузі соціальних і гуманітарних наук [14]. Цей перелік може бути значно розширений, оскільки студенти часто обирають освітні програми, які передбачають отримання подвійної або потрійної спеціальності.

У результаті проведеного дослідження визначено, що розробка освітньо-професійних програм підготовки бакалаврів гуманітарних наук 3 політології в університетах Англії та Уельсу базується на поєднанні таких соціо-ідеологічних засад як економічна ефективність вищої освіти, соціальний реконструктивізм, прогресивізм та когнітивний плюралізм, що впливають на визначення мети, змісту, методів навчання і оцінювання освітніх програм. 


\section{ПРОФЕСІЙНАПІДГОТОВКА БАКАЛАВРІВ ПОЛІТОЛОГІЇ В УНІВЕРСИТЕТАХ АНГЛІЇ ТА УЕЛЬСУ:}

ТЕОРІї,КОНЦЕПЩІї, ПДХОДИ

Відповідно до засад соціальної і економічної ефективності вищої освіти, метою професійної підготовки бакалаврів політології є задоволення поточних і майбутніх економічних потреб суспільства; зміст освітньо-професійних програм зосереджується на опануванні знаннями, уміннями і навичками, необхідними для майбутнього працевлаштування; методи викладання і навчання зорієнтовані на оволодіння уміннями і навичками, а також їх практичне застосування; методи оцінювання перевіряють здатність студентів до застосування отриманих знань, умінь і навичок [12].

У рамках соціального реконструктивізму програми підготовки політологів розглядаються як інструмент забезпечення соціальних реформ, стимулювання громадської активності; зміст освіти зосереджується на соціальних потребах, питаннях та ідеалах; методи навчання забезпечують взаємодію, групову роботу i залучення студентів до співпраці з громадою, а методи оцінювання вимагають залучення студентів до оцінювання власної роботи [16].

Важливу роль у процесі підготовки політологів в університетах Англії та Уельсу відіграють ідеї прогресивізму, що забезпечують студентам можливості для особистісного та інтелектуального розвитку, наголошують на самостійній роботі студента, визначають роль викладача як фасилітатора, пропонують методи оцінювання, що базуються на якісних показниках та намагаються проаналізувати процес навчання [11].

Домінуючими у процесі розробки та реалізації освітніх програм підготовки бакалаврів політології в університетах Англії та Уельсу $є$ ідеї когнітивного плюралізму, що забезпечують опанування широким спектром компетентностей; зміст освіти базується на розгляді комплексних спірних питань, аналізі вхідних даних з різних джерел та різноманітті результатів навчання; методи навчання забезпечують діяльність студента, викладач виступає фасилітатором; оцінювання базується на якісних показниках, що намагаються гарантувати різноманіття освітнього процесу [6].

Значний вплив на процес професійної підготовки політологів має теорія когнітивізму, яка розглядає процес обробки інформації особами, що навчаються, а також їхню здатність пов'язувати нову інформацію з уже набутими знаннями. Як зазначають Ертмер П.А. і Ньюбі Т.Дж.: “Роль викладача полягає не лише у допомозі студентам iз структуруванням їхніх знань, але й із осмисленням важливості того, що вони вивчають” $[5,53]$. Застосування теорії когнітивізму до організації освітнього процесу політологів $\epsilon$ особливо корисним при формуванні критикоаналітичної компетентності майбутніх фахівців у галузі політології, що забезпечує їм уміння проводити причинно-наслідковий аналіз політичних фактів і подій у системний і покроковий спосіб.

Професійна підготовка бакалаврів політології в університетах Англії та Уельсу значною мірою базується на концепції активного навчання, в основі якої лежить теорія конструктивізму, що наголошує на самостійному конструюванні знання і розуміння особами, що навчаються. Відповідно до конструктивістської парадигми, навчання $\epsilon$ ефективним за умови реалізації наступних умов: активне залучення студентів у процес пізнання; демократичне навчальне середовище; інтерактивні і студентоцентровані методи викладання і навчання; викладач як фасилітатор; заохочення відповідальності і автономності студентів у процесі навчання $[5,68]$. Значний вплив на формування теоретичних засад активного навчання мали теорія соціального конструктивізму, відповідно до якої навчання відбувається через соціальну взаємодію, а також ідеї, вперше запропоновані Ж.-Ж. Руссо і в подальшому розвинені Д. Дьюї і М. Монтессорі, які наголошували на актуальності i контекстуальності навчання [9, 24].

Провідні педагогічні дослідження процесу оволодіння політологічними знаннями засвідчують, що сприйняття політики базується натрьох шарах розуміння, щопов'язані з: 1) особистим досвідом та інтересами (демократія як спосіб життя), 2) ширшим соціальним контекстом (демократія як соціальна система), 3) державною політикою (демократія як форма правління) [4, 27]. Таким чином, прогресивні моделі отримання політологічних знань базуються на встановленні зв'язків між теоретичними постулатами за допомогою практичної діяльності [13,4 - 5].

У системі вищої освіти Англії та Уельсу домінує компетентнісний підхід до організації професійної підготовки бакалаврів політології, що передбачає орієнтацію на результати навчання. У рамках компетентнісного підходу освіта спрямована на формування здатності майбутнього політолога до самостійного опанування новими знаннями впродовж життя, найбільш повного виявлення та реалізації власного інтелектуального і творчого потенціалу, самовизначення та соціального інтегрування, розвитку індивідуальності, що створює умови для оволодіння високим рівнем професійної компетентності загалом, і культурою професійної 
діяльності зокрема [2, 46]. Застосування цього підходу забезпечує умови для максимального узгодження результатів освіти з потребами ринку праці, розробки і впровадження інноваційних освітніх технологій та підвищення якості надання освітніх послуг в цілому.

Формування інтегральної компетентності бакалавра політології передбачає оволодіння комплексом загальних і спеціальних компетентностей, у структурі яких ми виокремлюємо когнітивний, операційний та ціннісно-мотиваційний компоненти $[3,11]$. Загальними компетентностями бакалавра гуманітарних наук з політології є комунікативна, самоосвітня, міжособистісна, міжкультурна, міждисциплінарна, громадянська, інформаційнокомунікаційна, а до спеціальних компетентностей належать: суспільно-політична, науководослідницька, аналітична, прогностична, діагностична, конфліктологічна, управлінська [15].

Важливу роль у процесі організації професійної підготовки бакалаврів політології в університетах Англії та Уельсувідіграє міжкультурний підхід, що зумовлено загальними тенденціями до глобалізації економічного, політичного і культурного життя суспільства, а також специфікою окремих освітніх програм підготовки політологів, що пропонують спеціалізацію у вивченні політичної системи окремої країни. Таким чином, значна увага приділяється формуванню міжкультурної компетентності, що передбачає виховання відкритості до пізнання іншої культури, толерантності, поваги, позитивного сприйняття відмінностей між ціннісними системами різних культур і психологічної установки на співпрацю 3 представниками інших культур [6, 368].

Чільне місце у процесі професійної підготовки майбутніх фахівців у галузі політології займає міждисциплінарний підхід, що дозволяє розглядати будь-які суспільно-політичні проблеми крізь призму декількох дисциплін, інтегрувати дисциплінарні позиції з метою формування цілісної картини певної ситуації і вироблення iï комплексного вирішення [7, 322]. Застосування цього підходу обгрунтовується загальними тенденціями до ускладнення і диверсифікації політичного життя суспільства у контексті активних глобалізаційних процесів, а також мультитеоретичною сутністю політології, що створює значний потенціал для взаємодії 3 дисциплінами гуманітарного і природничого блоку.

У контексті аксіологічного підходу, який зосереджується на розвитку ціннісно-особистісної складової здобувача освіти, професійна освіта і підготовка майбутніх політологів повинна сприяти розбудові толерантності, справедливості, міжкультурного розуміння $[17,52]$. Цей підхід реалізується, значною мірою, через формування загальних компетентностей i отримання громадянської освіти шляхом волонтерської діяльності, практики, навчання через суспільнокорисну працю тощо.

Висновки і перспективи подальших розвідок. Професійна підготовка бакалаврів гуманітарних наук з політології в університетах Англії та Уельсу базується на комплексній інтеграції філософських, психологічних, педагогічних теорій, концепцій, підходів (соціальна та економічна ефективність, прогресивізм, когнітивний плюралізм, соціальний реконструктивізм, теорії когнітивізму, конструктивізму, концепція активного навчання, компетентнісний, міжкультурний, міждисциплінарний, аксіологічний підходи), що забезпечує якісну підготовку випускників до професійної і науково-дослідної діяльності, формування і розвиток високорівневих інтелектуальних, комунікативних, міжособистісних умінь і навичок, виховання соціальних i демократичних цінностей, почуття глобальної громадянськості, сприяння формуванню особистісної цілісності випускника.

Перспективи подальших наукових розвідок ми вбачаємо у дослідженні потенціалу застосування міждисциплінарного підходу у процесі розробки та реалізації освітньо-професійних програм підготовки бакалаврів політології, що зумовлено мультитеоретичною сутністю цієї галузі знань.

\section{ЛІТЕРАТУРА}

1. Гончаренко, С. Фундаменталізація професійної освіти. / С. Гончаренко // Ksztalcenie zawodowe: pedagogika i psychologia. - 2006. - № 7-C. 165 - 175.

2. Козлова, Н. Б. Развитие профессиональной компетентности будущего учителя иностранного языка в процессе иноязычной подготовки в вузе / Н. Б. Козлова // (Дис. на соискание науч. степени канд. пед. наук: спец. 13.00 .08 “Теория и методика профессионального образования"). - Магнитогорский государственный университет, Мангитогорск. -2003.

3. Михайличенко, М. Формування громадянської компетентності майбутніх учителів предметів гуманітарного циклу. / М. Михайличенко // (Автореф. дис. на здобуття наук. ступеня канд. пед. наук: спец. 13.00.04. “Теорія і методика професійної освіти”). Кіровоградський державний педагогічний університет імені Володимира Винниченка, Кіровоград. - 2007.

4. Battistoni, R. \& Hudson, W. (1997). Experiencing Citizenship: Concepts and Models for Service-Learning in Political Science. AAHE Series on Service-Learning in the Disciplines. Sterling, VA: Stylus Publishing, LLC.

5. Ertmer, P.A. \& Newby, T.J. Behaviorism, Cognitivism, Constructivism: Comparing Critical Features from an 


\section{ПРОФЕСІЙНАПІДОТОВКА БАКАЛАВРІВ ПОЛІТОЛОГІЇ В УНІВЕРСИТЕТАХ АНГЛІЇ ТА УЕЛЬСУ: ТЕОРІї,КОНЦЕПЩІї,ПЦДХОДИ}

Instructional Design Perspective. Performance Improvement Quarterly, 6(4). 50-72.

6. Evers, C.W. (2007). Culture, Cognitive Pluralism and Rationality. Educational Philosophy and Theory. Vol. 39, Issue 4, 364-382.

7. Greaves, J. \& Grant, W. (2010). Crossing the interdisciplinary divide: political science and biological science. Political Studies. Vol. 58 (2), 320-339.

8. Johnson, N. (1989). The Limits of Political Science. Oxford: Clarendon Press.

9. O’Neill, G. and McMahon, T. (2005) 'Student-centred learning: what does it mean for students and lecturers?' In O'Neill, G., Moore, S. and McMullin, B. (Eds.) Emerging Issues in the Practice of University Learning and Teaching. Dublin, Ireland: All Ireland Society for Higher Education.

10. Political Science, Encyclopedia Britannica. Retrieved from: https:/www.britannica. com/topic/political-science.

11. Reynolds, K.C. (1997). Progressive Ideals and Experimental Higher Education: The Example of John Dewey and Black Mountain College. Education and Culture. Vol. XIV, No.1, 1-9.

12. Sadlak J. (1978). Efficiency in Higher Education: Concepts and Problems. Higher Education. Vol. 7, No. 2, 213-220.

13. Sloam, J. (2010). A Pedagogy of Engagement in Higher Education. Paper Presented to the Political Studies Association of Ireland Annual Conference, Dublin Institute of Technology.

14. Standard Occupational Classification. Retrieved from: http://www.ons.gov.uk/ons/guide-method/classifications/ current-standard-classifications/soc2010/index.html.

15. Subject Benchmark Statement for Politics and International Relations (2015). Quality Assurance Agency for Higher Education. Retrieved from: http:// www.qaa.ac.uk/en/Publications/Documents/SBS-politics$\underline{15 . p d f}$

16. Taber, K. S. (2011). Constructivism as educational theory: Contingency in learning, and optimally guided instruction. In J. Hassaskhah (Ed.), Educational Theory. New York: Nova, 39-61.

17. Tomar, B. (2014). Axiology in Teacher Education: Implementation and Challenges. IOSR Journal of Research \& Method in Education. Vol. 4, Issue 2, Ver. III, 51-54.

\section{REFERENCES}

1. Honcharenko, S. (2006). Fundamentalizatsiia profesiinoi osvity [Fundamentalization of Professional Education]. Ksztalcenie zawodowe: pedagogika $i$ psychologia, no.7, pp.165-175. [in Ukrainian].

2. Kozlova, N. B. (2003). Razvitie professionalnoy kompetentnosti budushchego uchitelya inostrannogo yazyka $v$ protsesse inoyazychnoy podgotovki $v$ vuze [Development of Prospective Foreign Language Teacher's Professional Competency during Foreign Language Training at Higher Educational Establishments]. Candidate's thesis. Magnitogorskiy gosudarstvennyy universitet, Mangitogorsk. [in Russian]

3. Mykhailychenko, M. (2007). Formuvannia hromadianskoi kompetentnosti maibutnikh uchyteliv predmetiv humanitarnoho tsyklu [Development of
Prospective Humanities Teachers' Civic Competence] Extended abstract of candidate's thesis. Kirovohradskyi derzhavnyi pedahohichnyi universytet imeni Volodymyra Vynnychenka, Kirovohrad. [in Ukrainian].

4. Battistoni, R. \& Hudson, W. (1997). Experiencing Citizenship: Concepts and Models for Service-Learning in Political Science. AAHE Series on Service-Learning in the Disciplines. Sterling, VA: Stylus Publishing, LLC. [in English]

5. Ertmer, P.A. \& Newby, T.J. Behaviorism, Cognitivism, Constructivism: Comparing Critical Features from an Instructional Design Perspective. Performance Improvement Quarterly, 6(4), pp.50-72. [in English].

6. Evers, C.W. (2007). Culture, Cognitive Pluralism and Rationality. Educational Philosophy and Theory. Vol. 39, Issue 4, pp.364 - 382. [in English].

7. Greaves, J. \& Grant, W. (2010). Crossing the interdisciplinary divide: political science and biological science. Political Studies. Vol. 58 (2), pp.320 - 339. [in English].

8. Johnson, N. (1989). The Limits of Political Science. Oxford: Clarendon Press. [in English].

9. O’Neill, G. and McMahon, T. (2005). Student-centred learning: what does it mean for students and lecturers?' In O'Neill, G., Moore, S. and McMullin, B. (Eds.) Emerging Issues in the Practice of University Learning and Teaching. Dublin, Ireland: All Ireland Society for Higher Education. [in English].

10. Political Science, Encyclopedia Britannica. Retrieved from: https://www.britannica. com/topic/ political-science. [in English].

11. Reynolds, K.C. (1997). Progressive Ideals and Experimental Higher Education: The Example of John Dewey and Black Mountain College. Education and Culture. Vol. XIV, No.1,pp. 1 - 9. [in English].

12. Sadlak J. (1978). Efficiency in Higher Education: Concepts and Problems. Higher Education. Vol. 7, No. 2, pp.213-220. [in English].

13. Sloam, J. (2010). A Pedagogy of Engagement in Higher Education. Paper Presented to the Political Studies Association of Ireland Annual Conference, Dublin Institute of Technology. [in English].

14. Standard Occupational Classification. Retrieved from: http://www.ons.gov.uk/ons/guide-method/ classifications/current-standard-classifications/soc2010/ index.html. [in English].

15. Subject Benchmark Statement for Politics and International Relations (2015). Quality Assurance Agency for Higher Education. Retrieved from:http:// www.qaa.ac.uk/en/Publications/Documents/SBS-politics15.pdf [in English].

16. Taber, K. S. (2011). Constructivism as educational theory: Contingency in learning, and optimally guided instruction. In J. Hassaskhah (Ed.), Educational Theory. New York: Nova, pp.39-61. [in English].

17. Tomar, B. (2014). Axiology in Teacher Education: Implementation and Challenges. IOSR Journal of Research \& Method in Education. Vol. 4, Issue 2, Ver. III, pp.51- 54. [in English].

Стаття надійшла до редакції 25.09.2018 